\title{
Integration of CALL into the Teaching of College English Reading
}

\author{
Liming Sun \\ College of Foreign Language \\ Shijiazhuang University of Economics \\ Shijiazhuang, China \\ sunlm1976@163.com
}

\author{
Ni Wang \\ College of Foreign Language \\ Shijiazhuang University of Economics \\ Shijiazhuang, China \\ wangni2005@yahoo.com.cn
}

\begin{abstract}
Reforming the teaching mode by integrating CALL into college English reading teaching is a possible and efficient solution to the current situation of college reading teaching. The hypothesis about the efficiency of CALL and its feasibility in Chinese college reading courses are confirmed and computer will act as a device enabling the college students in China to have greater achievement and motivation in reading. The results of this study indicate that CALL is an effective instruction mode in teaching English reading and have practical implications for the administrators, teachers, and students.
\end{abstract}

Keywords- CALL; teaching of English; reading; internet; multimedia; integration

\section{INTRODUCTION}

In December of 2002, the State Education Ministry carried out the "College English Teaching Reform" project in which two main tasks were to execute a new College English Curriculum Requirements and to construct networkbased multimedia dimensional teaching system. The extensive use of computer in the learning-teaching process and rapid development of multimedia technology make possible the reform of conventional reading teaching methodologies and the modern teaching model of studentcentered, learning-centered and task-centered [1].

Recently, many empirical studies have been carried out to integrate CALL into College English reading teaching to determine and evaluate the effectiveness of various kinds of computer uses, programs and courseware. Many studies show benefits of CALL in relation to reading. However, how to apply the results of early studies in new condition, and combine the use of courseware with abundant teaching resources and new technology the Internet provides, becomes an important question for CALL researchers. In view of this, it is time to better understand what CALL is, study its effectiveness and feasibility in application of Chinese college English reading, and if applicable, further consider how to integrate CALL in a meaningful way.

Inspired by the thoughts above, a case study is carried out in a group of sophomores in Shijiazhuang University of Economics, which examines the effectiveness and the appropriateness of the application of a New College English courseware and the internet in the area of English reading teaching. It is hypothesized that college students will achieve and enjoy more in CALL reading and it is hoped that the results will provide evidence and pedagogical support for the application of computer-assisted language learning in College English reading teaching.

\section{RESEARCH PROCEDURE}

\section{A. Research objective}

The study is made to integrate CALL into college English reading instruction to examine and access the effectiveness of CALL on learners' writing, reading comprehension, attitude, interest, computer experiences, their reactions to CALL and expectations to the technology' potential of EFL learners. The independent variable for quantitative study is the instructional formats: CALL or the traditional teacher-centered instruction. The dependent variables are writing, reading comprehension as measured by College English Test Band 4 examination paper of June in 2006 and June in 2007, and learners' attitude, interest, computer experiences, their reactions to CALL and expectations to the technology' potential measured by the questionnaire.

\section{B. Hypotheses}

It is hypothesized that students who receive CALL perform better than their counterparts who receive only traditional teacher-centered instruction in the areas of writing and reading comprehension. And they are comparatively more motivated and interested in CALL English reading. And it is further supposed that CALL in English reading will have greater potentials in China.

\section{Subjects}

Participants were sophomores with varied academic backgrounds at the Shijiazhuang University of Economics during the Spring 2012 semester. They spend four credit hours in English each week. Teaching of English is administered in big classes, with the number of students around 100 on average. Altogether, there are 202 students (around $48 \%$ of which are female students) in two classes. One class is from the Chinese department with 100 students who are Broadcast majors and Cultural Industry Management majors, and receive the traditional instruction. They are the control group (CG in short). The other one is from PE department with 102 students majored in Public Sports who receive CALL. They are the experiment group (EG in short). Their English proficiency level ranged from Band 1 to Band 3, and they were assumed to have no 
difficulty in using computers as a tool since they had gained basic application knowledge in computer classes.

\section{Questionnaire}

The students' reactions to the CALL English reading course are sought through a courseware evaluation questionnaire administered at the end of the course which contains some 5-point scale, open-ended questions on a wide range of topics in the college English reading courses. The questionnaire seeks to ascertain students' attitude, interest, perceptions of the usefulness of computer assisted English reading, their views on its advantages and disadvantages, their attitudes towards the role of CALL, their preferred mode of delivery in different activities, and their evaluation of the interface design. In total, about 202 questionnaires had been distributed and 202 valid responses were received. The questionnaire was adapted from Gardner's Battery of Test, Schultz's Questionnaire for In-class Response-group Work and Inter-Change Composition Response-group Questionnaire, Kamhi-Stein's Computer Use Survey, and Cheng Youqiang's Survey of Attitudes towards Learning English, Interests in WBI and Self-efficacy [2]. Efforts are made to make the questionnaire more valid and reliable. While preparing the items, the researcher owes much to the help of some colleagues. Several colleagues are invited to look at the items to see if they make sense. The inappropriate items are revised according to their opinions. Some students for whom the questionnaire is planned are also asked to look at each of the items and circle any word they do not understand. Adjustments are made based on their feedback.

\section{RESEARCH RESUlTS}

ANOVA (Analysis of Variance) was used to analyze data obtained from the research. All inference testing was done at the 0.05 alpha levels. Descriptive statistics for the two sections of CET-4 (i.e. Writing and Reading Comprehension) were calculated for the two groups over pre- and post-CALL intervention. The findings of the study are presented in the following four sections: reading comprehension; reading comprehension; attitude toward English learning; computer experiences; reactions to CALL application; expectations to the technology's potential in English learning.

\section{A. Reading comprehension}

The data of English reading proficiency are analyzed using an ANOVA technique. As shown in the table, the T value does exceed the critical value of 2.021. Therefore, hypothesis that the English reading proficiency of students who receive CALL will be statistically different than that of students who receive teacher-centered instruction is accepted at 95\% confidence level. The results show that the subjects in the experiment group performed better than their counterparts in the control group. The findings in this study are in accordance with Arroyo's, Adler-Kassner and Reynolds's, Song Li and Zhao Shifeng's, and Huang Ruoyu and Chen Wenguan's conclusion that CALL often results in better performance and higher motivation. The findings also echo Sankaran, Sankaran and Bui's conclusion that students of non-English background may feel more comfortable studying by themselves and interacting with peers in written format.

TABle 1. ANOVA COMPARISONS OF CET PERFORMANCE OVER THE INTERVENTION PERIOD

\begin{tabular}{|l|l|l|l|l|l|l|}
\hline (I)group & (J)group & df & T & M.D. & Std.E & Sig. \\
\hline CG-pre & CG-post & 44 & -.513 & -.776 & 1.4202 & .574 \\
\hline EG-pre & EG-post & 44 & -3.572 & -4.913 & 1.4202 & .001 \\
\hline CG-post & EG-post & 44 & -2.181 & -3.000 & 1.4202 & .03649 \\
\hline
\end{tabular}

Dependent Variable: reading

\section{B. Reading comprehension}

TABLE 2. ANOVA COMPARISONS OF ATTITUDE OVER THE INTERVENTION PERIOD

\begin{tabular}{|l|l|l|l|l|l|l|}
\hline (I)group & (J)group & df & T & M.D. & Std.E & Sig. \\
\hline CG-pre & EG-pre & 18 & .532 & .1000 & .21149 & .639 \\
\hline EG-pre & EG-post & 18 & -3.088 & -.6430 & .21149 & .005 \\
\hline CG-pre & CG-post & 18 & .533 & .1001 & .21149 & .636 \\
\hline
\end{tabular}

Dependent Variable: attitude

In the questionnaire, subjects are asked to rate their attitude towards English learning on a five point scale. Data of attitude in English learning were analyzed using an ANOVA technique. At the pretest, the comparison of the learners' attitude in the two groups yielded a $T$ value of 0.532 , within the range of $[-2.101,2.101]$. That is to say, there was no significant difference between the two groups in terms of learning attitude. For EG, significant change can be found since the $t$ value was -3.088 , beyond the range of [$2.101,2.101]$. For CG, no significant change can be found since the $t$ value was 0.533 , within the range of $[-2.101$, 2.101]. Both the two groups experienced significant change in learners' attitude during the experiment period. The findings are consistent with the results drawn by other researchers. According to those researchers, students of nonEnglish cultural backgrounds tend to be motivated by CALL and the Internet in learning English as a foreign or second language.

Throughout the study, subjects in the experiment group were enthusiastic in reading the authentic materials, completing the assignments, and discussing with the instructor and their peers on the network.

\section{Attitude toward English learning}

TABLE 7. ANOVA COMPARISONS OF INTEREST OVER THE INTERVENTION PERIOD

\begin{tabular}{|l|l|l|l|l|l|l|}
\hline (I)group & (J)group & df & T & M.D. & Std.E & Sig. \\
\hline CG-pre & EG-pre & 18 & -.046 & -.0102 & .19264 & .959 \\
\hline EG-pre & EG-post & 18 & -3.175 & -.6400 & .19264 & .002 \\
\hline CG-pre & CG-post & 18 & -.272 & -.0211 & .19264 & .914 \\
\hline
\end{tabular}

Dependent Variable: interest

In the questionnaire, subjects are asked to rate their interest in English learning on a five point scale. The data of English learning interest were analyzed using an ANOVA technique. As shown in the table, the $t$ value drawn from the comparison of the two groups at the beginning of the experiment was -0.046 , within the range of [-2.101, 2.101], 
i.e., there was no significant difference in the learning interest of the two groups.

As to EG, the T value -3.175 , beyond the range of [2.101, 2.101], indicates that significant changes took place in the learning interest of the groups. As to CG, the t value .272 , within the range of $[-2.101,2.101]$, indicates that there was no significant difference in the learning interest of the group.

\section{Computer experience}

In the questionnaire, subjects are asked to rate their computer knowledge on a five point scale. Most college students have adequate basic knowledge about computer usage with almost $74 \%$ of students giving it a rating of four or higher. That is to say, the college students have great interests in the usage of computers. They have good basic knowledge of computers and how they work, and most of them are familiar with the computers' word processing and typing and. But they are not familiar with the some application packages and reading courseware. And the result is not unexpected in modem China, since some basic computer courses are compulsory in most colleges. There is reason to say that college students' good mastery of computer and great interests in using it have made the application of CALL possible.

\section{E. Reactions to CALL application}

Generally speaking, $80 \%$ of the students who use the courseware indicate that they like what they have used. 75\% of the respondents state that they believe the courseware is useful in helping them with their studies and 93.3\% of the students prefer CALL English teaching. their preferred mode of delivery in different activities, and their evaluation of the interface design. In total, about 202 questionnaires had been distributed and 202 valid responses were received.

\section{F. Expectation and implication}

In this part, the students are allowed to express their opinions more freely in either English or Chinese on the computer-assisted reading instruction. Students' responses in item 10 are interpreted as follows: I believed the CALL to be effective and interactive; The computer makes reading more interesting; It is a good way of improving reading skills. Using the computer helps students to concentrate more. The screen is tiring for the eyes.

A certain percentage of students agree that they prefer traditional reading materials while, on the other hand, they enjoyed using the computer, which seems somewhat a contradiction. Most computer users will agree that reading on a computer is tiring for the eyes and not as pleasant as reading from paper. They have fairly high expectations of what the computer might offer them and they seem to have full confidence in the efficiency of CALL. Based on the data gathered in the questionnaire, the students agree with each other that the Internet is what they are most interested in and must be the most powerful tools for language learning, especially English reading. They are so eager to learn more about Internet and long for the opportunities to make full use of this powerful language learning tool.

\section{CONCLUSION}

The questionnaire probes general reactions to the use of CALL in EFL learners' performance on writing, reading comprehension, attitudes to its learning efficiency and attitudes to CALL as a study tool. The hypothesis about the efficiency of CALL and its feasibility in Chinese college reading courses are confirmed and computer will act as a device enabling the college students in China to have greater achievement and motivation in reading. The results of this study indicate that CALL is an effective instruction mode in teaching English reading, which is evidenced in the statistically significant gains on pretest-posttest means in the reading proficiency section of CET-4. The findings of this study have practical implications for the administrators, teachers, and students of EFL.

In contrast to the traditional teacher-centered instruction, CALL provides the students with more authentic language environment [3]. Foreign language instructors and course designers should also take advantages of the text-based feature of the Internet to promote student reading proficiency. With the application of CALL, many problems haunting on College English teaching in China can be solved, such as low ratio of teacher to student. Under such circumstances, students learn by themselves, the teacher plays the role of the instructor and facilitator, and therefore it does not require a large number of teachers. Another good example in case is the insufficient reading materials. From the Internet, students may virtually find any reading material written by native speakers of English. CALL is effective in motivating EFL learners, which is shown in the statistically significant findings in the pretest-posttest means of the motivation for reading among college students, development of wider knowledge and higher expectation for the further application of CALL in college English. It is strongly recommended that administrators and instructors use CALL as a motivator in promoting students attitude and interest in English learning [4]. With the help of CALL, they feel comfortable and efficient with reading and are very receptive to any learning activities that involve the computer. Increased motivation leads to increased language use, which in turn leads to improved proficiency. Not only enormous amount of authentic language materials are downloaded from the Internet to supply learners with abundant input, but different types of files, audio, video, or in written format, provides learners with the opportunity of practicing different skills and functioned better to arouse their interest.

The flexibility and capability of CALL make it possible to teach virtually anything from problem-solving skills to relatively simple learning by offering text and with animation and sound [5]. CALL appeals to varied learning modalities and consequently meets the diverse needs of individual students. With CALL, students can learn at a comfortable pace, interact directly and continually with computers, get hints and feedback from the computer as necessary, understand how well they are doing and what they have achieved, study as much as they want. With the aid of the Internet and CD-Rom based materials, teachers can 
quickly access documents addressing individual student needs.

\section{REFERENCES}

[1] Blok, H., Oostdam, R., Otter, M.E., and Ovenmaat, M., Computer Assisted Instruction in Support of Beginning Reading Instruction: A Review. Review of Educational Research, 2002, 72 (1)

[2] Davis, J.N.\&Lyman-Hager, M., Computers and L2 reading: student performance, student attitudes. Foreign Language Annals. 1997, 30 (1): 58-72
[3] Lomicka, L., To gloss or not to gloss: An investigation of reading comprehension on-line. Language Learning and Technology, 1997, 1: 41-50

[4] Lynch, Lisa et al., Computer-assisted reading intervention in a secondary school: an evaluation statement, British Journal of Educational Technology, 2000, 31 (4)

[5] Underwood, Jean D.M., A comparison of two types of computer support for reading development, Journal of Research in Reading, 2003, 23 (2) On the Intelligent CALL in the 1990's. Computers and the Humanities.23, (71-84) 